\title{
The Relationship Between Pain, Muscle Strength and Lower Extremity Function in Patients with Knee Osteoarthritis
}

\author{
Sevtap Günay Uçurum ${ }^{1}$, Yasemin Kayalı ${ }^{\circledR}$ \\ 1'zmir Katip Çelebi Üniversitesi, Sağıık Bilimleri Fakültesi Fizyoterapi ve Reahabilitasyon Bölümü, İzmir, Turkey \\ ${ }^{2}$ IZmir Katip Çelebi Üniversitesi, Atatürk Eğitim Araştırma Hastanesi Fizik Tedavi ve Rehabilitasyon Ünitesi, İzmir, Turkey \\ Address for Correspondence: Sevtap Gunay Uçurum, E-mail: sevtapgunay.tfd@gmail.com \\ Received: 20.10.2019; Accepted: 18.12.2019; Available Online Date: 27.01.2020 \\ (OCopyright 2019 by Dokuz Eylül University, Institute of Health Sciences - Available online at www.jbachs.org
}

Cite this article as: Günay Uçurum S, Kayalı Y. The Relationship Between Pain, Muscle Strenght and Lower Extremity Function in Patients with Knee Osteoarthritis. J Basic Clin Health Sci 2020; 1:72-76

\begin{abstract}
Objective: Osteoarthritis $(\mathrm{OA})$ is a problem causing functional disability and impairing quality of life. The presence of factors that may cause functional disability is important for OA patients. Therefore, we aimed to investigate the relationship between pain, muscle strength and lower extremity function in patients with osteoarthritis.

Methods: A total of 58 patients ( 5 male, 53 female) with a mean age of $60.63 \pm 8.50$ were included in the study. Pain level by Visual Pain Scale (VAS), muscle strength by Jamar Hand Held Dynamometer, and lower extremity functional level by Lower Extremity Functional Scale were evaluated.

Results: The mean VAS value at rest was $3.54 \pm 0.33$, while the mean VAS value during the activity was $6.28 \pm 0.28$. The lower extremity functional scale results were $36.01 \pm 1.87$ points. When comparing the muscle strength of the knee with and without OA, while there is a difference between the extension muscle strengths, no difference was found between flexion muscle strengths $(p=.001, p=.580)$. Knee OA knee muscle strength was positively correlated with non-OA knee muscle strength and lower extremity functional scale $(p<0.05)$. In addition, there was a negative correlation between functional level and activity pain $(p<0.05)$.

Conclusion: Knee muscle strength in osteoarthritis affects non-osteoarthritis knee muscle strength and lower extremity function. As muscle strength decreases, muscle strength and function level of the non-affected knee decreases. In addition, as the activity pain increases, the lower extremity functional level deteriorates. In the treatment of knee OA, reducing pain and increasing muscle strength may be important for improving function.
\end{abstract}

Key words: Osteoarthritis, pain, muscle strength, lower extremity function

\section{INTRODUCTION}

Osteoarthritis of the knee (OA) primarily affects the articular cartilage and the subchondral bone of the synovial joints in adults, its prevalence increases in accordance with the age and it is a more common musculoskeletal disease in women $(1,2)$ Patients with OA may experience joint pain on only one side of the body and it primarily affects the knees, hands, hips, feet, and spine (3). When the cartilage wears out, it creates protrusions in the bones, abnormal areas of hardening, and fluid-filled areas within the bone marrow known as subchondral cysts. The pain is caused by the deformation of the bones and accumulation of fluid in the joints as the disease progresses. The pain is relaxed while resting and it's exacerbated by moving the joint or putting weight on it (4).
Typical findings of knee OA are joint stiffness, reduced strength of quadriceps femoris muscle (QFM), pain, physical disability that restricts joint function, and reduced physical fitness (5). Pain and loss of strength in the muscles around the knee affect lower extremity functions and negatively affect daily life activities such as climbing stairs, walking, standing, balancing and it might make the patient more dependent.(2,6). Oiestad and his colleagues conducted a systematic review suggesting that there may be a correlation between the weakness of the knee extensor muscle and the risk of developing knee OA. (7). With the weakening of the muscles around the joint, joint load may increase, joint faces may wear out and pain may occur. 
Knee OA has a number of physiological and neuromuscular disorders that cause people's functional levels to change. Increased neuromuscular deficits, particularly impaired balance and proprioception, muscle weakness, decreased strength and joint pain, can affect postural control mechanisms and the ability to protect oneself against falling. Pain, loss of function and muscle weakness may be among the factors that increase physical disability. Impaired muscle strength and increased pain levels may be important causes of functional loss $(8,9)$. In lower extremity arthritis, there is often a decreased level of muscle strength. There is a complex relationship between functional status, cartilage degeneration, and sensorimotor dysfunction that takes origin from muscles around the joint. Muscular weakness further increases functional deficiencies in patients with knee OA (10). It is very important to establish the relationships between muscle strength, pain and functional level for the treatment of OA cases and long-term quality of life.

Even though there have been studies on this subject, studies examining pain, muscle strength and lower extremity function and their relationship with one another are insufficient. For this reason, in this study, we aimed to examine the relationship between pain, muscle strength and lower extremity function in patients with osteoarthritis.

In patients with $\mathrm{HO}$ osteoarthritis, there is no correlation between pain, muscle strength and lower extremity function.

In patients with $\mathrm{H} 1$ osteoarthritis, there is a relationship between pain, muscle strength and lower extremity function.

The ethics committee approval of this study was obtained from the Non-Interventional Clinical Research Ethics Committee of İzmir Katip Çelebi University (Decision No: 1, Date: 23.01.2019).

\section{MATERIALS AND METHODS}

This study included patients who admitted to the Physical Therapy and Rehabilitation Clinic and were diagnosed with osteoarthritis. The criteria for participation in the study were to be over 40 years old, to be diagnosed with osteoarthritis according to the American College of Rheumatology criteria, to have stage 1-3 symptomatic knee OA according to the Kellgren-Lawrence scale, to be able to walk independently on its own, to have no other pathology that could cause knee pain other than knee OA, to have no waist or hip pathology that could affect the knee, and to voluntarily participate in the study. The criteria for exclusion from the study are having undergone any surgical procedures in the last 6 months, having a chronic disease such as coronary heart disease, cancer, Chronic Obstructive Pulmonary Disease (COPD), uncontrolled hypertension, rheumatic disease and having to be included in any physical therapy program in the last 6 months, being morbidly obese (BMI > 40), having undergone arthroplasty, being exposed to advanced degenerative changes (stage 4), and having a cooperative dysfunction.
All patients that met the criteria for inclusion and agreed to participate in the study were informed in writing and verbally about the evaluation forms used and the "Informed Consent Form" was signed.

\section{Measurements}

In the detailed histories of the patients included in the study; physical characteristics such as age, height, body weight, body mass index (BMI); demographic characteristics such as gender, marital status, education level, occupation and their medical history including CV, family history and drug information will be recorded in the patient evaluation form

Pain assessment of patients will be evaluated with the Visual Analog Scale, their muscle strengths will be evaluated with HandHeld Dynamometer and the functional status of the patients will be evaluated with the Lower Extremity Functional Scale.

Visual Analog Scale: It is a scale of $100 \mathrm{~mm}$ long horizontal line that determines the severity of pain, $0 \mathrm{~mm}$ meaning that there is no pain and $100 \mathrm{~mm}$ meaning that there is unbearable pain. People are asked to put a sign on this horizontal line indicating the severity of the pain they feel. The results are recorded in $\mathrm{mm}$ (11).

Muscle Strength Test: Measurements will be made by handheld dynamometer on the bed with hips and knees at $90^{\circ}$ flexion, feet free, arms crossed over the chest and seated without support. People in the sitting position will be asked to lift and hold their leg up from the knee and their strength of holding the leg in this position against the device for 3 seconds will be measured. The same procedure will be done to measure the strength of holding the bent knee while the leg is bent in the sitting position. Right, and left knee extensor and flexor muscle strengths will be evaluated (12).

Lower Extremity Functional Scale: The Lower Extremity Function Scale (LEFS) is a scale aimed at evaluating the functional status of patients with musculoskeletal dysfunction affecting the lower extremity. It consists of 20 items, each with five possible categories of numerical responses (0-4). Its validity and reliability were confirmed by Çıtaker et al. (13).

\section{Statistical Method}

We used the G*Power software version 3.1.9.2 (Heinrich-HeineUniversit€at Deusseldorf, Deusseldorf, Germany) to determine the required sample size for this study and a medium effect size (0.50). We selected 58 participants with a power of at $95 \%$ at an a level of .05, in our a priori power analyses.

The analysis of all the data obtained was done using the statistical program "SPSS 22.0 for Windows". Whether the data showed a normal distribution or not was examined with the Shapiro Wilks test. Continuous variables will be expressed as mean standard deviation or median (interquartile range) and categorical variables as percent (\%). Correlation analysis will be evaluated by Pearson/ Spearman Correlation Analysis. The statistical significance level will be considered as $p<0.05$. 


\section{RESULTS}

Socio-demographic characteristics, pain, muscle strength and lower extremity functional scale results of the individuals participating in the study were shown in Table-1.

When comparing the knee muscle strength of the patients with $\mathrm{OA}$ and the ones who don't have OA, it was found that there was a difference between their extension muscle strength, while there was no difference between their flexion muscle strength. $(p=, 001$, $p=, 580$ ) (Table 2) When the relationship between the patient's muscle strengths was examined, it was seen that there was a relationship between the muscle strength of the knee with OA and the muscle strength of the knee with non-OA. In particular, there was a strong correlation between knee extension force with $\mathrm{OA}$ and non-OA knee extension force, and between knee flexor strength with $\mathrm{OA}$ and non-OA knee flexor strength $(\mathrm{p}<0.05)$. It was also found that the functional level of the lower extremity had a relation with activity pain and muscle strength $(p<0.05)$, while it did not show any relation with rest pain $(p>0.05)$. (Table 3 )

\section{DISCUSSIONS}

In this study, the extensor muscle strength decreased especially in the knee joint with osteoarthritis, but there was no significant decrease in flexor muscle strength and that muscle strength in both knee joints was associated with each other and we also found that knee extension force with $O A$, in particular, had a high relationship with other knee extension force, and knee flexor strength with $\mathrm{OA}$ also had a high relationship with other knee flexor strength. We have also found that lower extremity function is adversely affected and the functional level is associated with activity pain and muscle strength.

In patients with knee osteoarthritis, the effect of muscle strength around the knee is an important factor as it affects the stability and load-bearing capacity of the knee joint (14). Studies show
Table 1. Demographic information, pain, muscle strength and lower extremity functional scale results of individuals

\begin{tabular}{lc}
\hline Variables & Mean $\pm \mathbf{S S} / \%$ \\
\hline Age (years) & $60,63 \pm 8,50$ \\
Height (cm) & $162,06 \pm 14,62$ \\
Weight (kg) & $81,25 \pm 13,10$ \\
Gender (\%) & \\
$\quad$ Female & $53(91.4)$ \\
$\quad$ Male & $5(8,6)$ \\
Education Level (\%) & \\
$\quad$ Illiterate & $13(22,4)$ \\
Primary school & $31(53,4)$ \\
Middle School & $4(6,9)$ \\
High school & $8(13,8)$ \\
University & $2(3,4)$ \\
Alcohol (\%) & \\
$\quad$ Yes & $0(0)$ \\
No & $58(100)$ \\
Smoking & \\
Yes & $1(1,7)$ \\
No & $57(98,3)$ \\
Pain & \\
Rest pain & $3,54 \pm, 33$ \\
Activity pain & $6,28 \pm, 28$ \\
Muscle strength (kg) & \\
OA Knee Extantion & $14,63 \pm, 43$ \\
OA Knee Flexion & $10,65 \pm, 33$ \\
Non-OA Knee Extension & $15,66 \pm, 41$ \\
Non-OA Knee Flexion & $10,78 \pm, 36$ \\
LEFS & $36,01 \pm 1,87$ \\
\hline
\end{tabular}

LEFS: Lower Extremity Function Scale

Table 2. Comparison of knee muscle strength of patients with and without OA

\begin{tabular}{lcc} 
Muscle Strength & Mean $\pm \mathbf{S S}$ & p \\
OA Knee Extantion & $14,60 \pm 3,24$ &, 001 \\
Non-OA Knee Extension & $15,66 \pm 3,09$ & \\
OA Knee Extantion & $10,60 \pm 2,54$ &, 580 \\
Non-OA Knee Flexion & $10,72 \pm 2,74$ &, \\
\hline
\end{tabular}

OA: osteoarthritis, $\mathrm{p}<0.05$

\begin{tabular}{|c|c|c|c|c|c|c|c|}
\hline & & $\begin{array}{l}\text { Rest } \\
\text { Pain }\end{array}$ & $\begin{array}{l}\text { Activity } \\
\text { Pain }\end{array}$ & OA KE & $\begin{array}{l}\text { OA } \\
\text { KF }\end{array}$ & $\begin{array}{c}\text { N.OA } \\
\text { KE }\end{array}$ & N.OA KF \\
\hline Activity pain & Pearson & ,210 & 1 & & & & \\
\hline \multirow{2}{*}{ OA KE } & Pearson &,- 038 &,- 178 & 1 & & & \\
\hline & $\mathrm{p}$ & ,778 & , 182 & & & & \\
\hline \multirow[t]{2}{*}{ N.OA KE } & Pearson & ,086 &,- 189 & ,757** &, $351^{* *}$ & 1 & \\
\hline & $\mathrm{p}$ &, 522 & , 155 &, 000 &, 007 & & \\
\hline \multirow{2}{*}{ N.OA KF } & Pearson &,- 055 &,$- 310^{*}$ &, $447^{* *}$ & $829^{* *}$ &, $466^{* *}$ & 1 \\
\hline & $\mathrm{p}$ & ,683 &, 018 &, 000 &, 000 &, 000 & \\
\hline \multirow{2}{*}{ LEFS } & Pearson &,- 202 &,$- 380^{* *}$ & $358^{* *}$ &, $278^{*}$ &, $281^{*}$ &, $354^{* *}$ \\
\hline & $\mathrm{p}$ & , 129 &, 003 &, 006 &, 035 &, 033 &, 006 \\
\hline
\end{tabular}

OA KE: OA Knee Extantion, OA KF: OA Knee Flexion, N.OA.KE: Non OA Knee Extantion, N.OA.KF: Non OA Knee Flexion, LEFS: Lower Extremity Function Scale, p<0.05, Spearman correlation test 
that knee extensor muscle strength is generally decreased. In their study, Liikavainio and colleagues showed that quadriceps muscle strength decreased by $13-26 \%$ in male patients with knee osteoarthritis compared to healthy patients (15). In their study of women with knee osteoarthritis, Riann and colleagues found that the group without osteoarthritis had a $22 \%$ higher quadriceps muscle strength (16). Lewek and his colleagues evaluated the isometric quadriceps strength of 12 male and female knee OA patients with an average age of 52 and found that isometric quadriceps muscle strength of the knee with OA was low (17). We've also found in this study that quadriceps muscle strength of the knee with OA decreased significantly compared to the other side muscle strength. Although there are studies evaluating quadriceps muscle strength in patients with $O A$, there are not many studies found to be evaluating hamstring muscle strength. Essentially, in terms of stability and function of the knee joint, the hamstring muscle group is also an important muscle group. Hortobagyi and his colleagues found that muscle strength balance around the knee is important in patients with OA and should be investigated (18). In their study, they found that the muscle strength of the hamstring was low at high speed. We found no difference between $O A$ and non-OA muscle strength in this study. We believe that this is due to the fact that we have evaluated muscle strength at an isometrically stable point and that we could not show the effect of functional muscle strength. Furthermore, when we examined the relationship between OA and non-OA knee muscle strength, we found that knee flexion and extension muscle strength with OA were positively correlated with each other and with non-OA knee muscle strength. Considering that muscle weakness is a risk factor for OA (19), it is possible that people with unilateral OA may increase the risk of developing OA over time due to decreasing muscle strength on the other knee, and therefore, the non-OA knee muscle strength should be taken into account in the treatment and preventive programs to be implemented.

Harrison conducted a study of patients with knee osteoarthritis in the 50-84 age range and found that the functionalities of the patients were affected (20). In their study, Gürkan and his colleagues showed that knee osteoarthritis leads to a decrease in physical functionality and it affects the quality of life (21). Similarly, Bacon and his colleagues conducted a study that showed muscle strength and function of patients with osteoarthritis were affected, that there was a relationship between muscle strength and function, and that the decrease in muscle strength adversely affected the function. In their study, Chun and his colleagues investigated the factors that affect physical performance and found that while muscle strength affects physical performance, pain does not (22). There are different results in the literature on this subject. This study found that the lower extremity functions of our cases were affected. It was also found that lower extremity function is in positive correlation with muscle strength with and without $\mathrm{OA}$, and that extremity function level lowered as the strength decreased. While at the same time, it was found that the lower extremity function had a negative relationship with the pain caused by the night and with activity and that the function was negatively affected and decreased as the pain increased. We think that the pain and muscle strength that affects the function are related to one another. Increased pain during activity can cause people to restrict their function sparingly due to increased pain and may adversely affect their function by resulting in a decrease in muscle contraction force. Over time, it is possible for people to avoid moving to control the increased pain caused by activity and that they move to a more inactive state by reducing their function, which can negatively affect their muscle strength and lower extremity function. In future studies, more detailed evaluations are needed to discuss these results.

High number of subjects and an objective measurement of muscle strength are the strengths of our study. This study has some limitations: 1. Only OA cases were taken and the comparison of OA and non-OA cases were made. The inclusion of a healthy control group in the study may produce better results for comparisons. 2. Muscle strength evaluation was carried out as an evaluation of isometric muscle strength in a static position. The dynamic or functional evaluation may be good for evaluating changes in muscle strength and their reflection on function. 3. In order to determine when muscle strength and function started in patients and how effective the duration is in these interactions, forming a subgroup based on complaints and diagnosis times might provide valuable information in terms of managing treatment programs.

Muscle strength is affected in patients with osteoarthritis and the side without osteoarthritis also affects muscle strength. At the same time, pain, especially during activity, also affects muscle strength and lower extremity function. When creating protective and therapeutic programs, the decrease in pain and muscle strength should be taken into consideration and it should be noted that the muscle strength in the healthy knee could also be affected.

\section{Informed Consent: All participants}

Compliance with Ethical Standards: The ethics committee approval of this study was obtained from the Non-Interventional Clinical Research Ethics Committee of Izmir Katip Çelebi University(Decision No: 1, Date: 23.01.2019)

Peer-review: Externally peer-reviewed.

Author Contributions: Concept - SGU, YK; Design - SGU, YK; Supervision - SGU, YK Fundings - SGU; Materials - SGU, YK; Data Collection and/or Processing - SGU, YK; Analysis and/or Interpretation - SGU, YK; Literature Search - SGU, YK; Writing Manuscript - SGU, YK Critical Review - SGU

Conflict of Interest: No conflict of interest was declared by the authors.

Financial Disclosure: The authors declared that this study has received no financial support. 


\section{REFERENCES}

1. Chen D, Shen J, Zhao W, et al. Osteoarthritis: toward a comprehensive understanding of pathological mechanism. Bone Res 2017;5:16044. [CrossRef]

2. Ögüt $H$, Güler $H$, Yıldızgören $M T$, Velioğlu $O$, Turhanoğlu AD. Does Kinesiology Taping Improve Muscle Strength and Function in Knee Osteoarthritis? A Single-Blind, Randomized and Controlled Study. Arch Rheumatol 2018;33:335-343. [CrossRef]

3. Grindrod KA, Marra CA, Colley L, et al. After patients are diagnosed with knee osteoarthritis, what do they do? Arthritis Care Res (Hoboken) 2010;62:510-515. [CrossRef]

4. Duman I, Taskaynatan MA, Mohur H, Tan AK. Assessment of the impact of proprioceptive exercises on balance and proprioception in patients with advanced knee osteoarthritis. Rheumatol Int 2012;32:3793-3798. [CrossRef]

5. Dawson J, Linsell L, Zondervan K, et al. Epidemiology of hip and knee pain and its impact on overall health status in older adults. Rheumatology (Oxford) 2004;43:497-504. [CrossRef]

6. Sanchez-Ramirez DC, van der Leeden $M, K n o l ~ D L$, et al. Association of postural control with muscle strength, proprioception, self-reported knee instability and activity limitations in patients with knee osteoarthritis. J Rehabil Med 2013;45;192-197. [CrossRef]

7. Oiestad BE, Juhl CB, Eitzen I, Thorlund JB Knee extensor muscle weakness is a risk factor for development of knee osteoarthritis. A systematic review and meta-analysis. Osteoarthritis Cartilage 2015;23:171-177. [CrossRef]

8. Kus G, Yeldan I. Strengthening the quadriceps femoris muscle versus other knee training programs for the treatment of knee osteoarthritis. Rheumatol Int 2019;39:203-218. [CrossRef]

9. Hunter DJ, McDougall JJ, Keefe FJ. The symptoms of osteoarthritis and genesis pain. Med Clin North Am 2009;93:83-100. [CrossRef]

10. van der Esch M, Steultjens M, Harlaar J, Knol D, Lems W, Dekker J. Joint Proprioception, Muscle Strength, and Functional Ability in Patients with Osteoarthritis of the Knee. Arthritis Rheum 2007;57:787-793. [CrossRef]

11. Boonstra AM, Schiphorst Preuper HR, Reneman MF, Posthumus JB, Stewart RE. Reliability and validity of the visual analogue scale for disability in patients with chronic musculoskeletal pain. Int J Rehabil Res 2008;31:165-169. [CrossRef]
12. Vardar Yağlı N, Şener G, Sağlam M, et al. Associations among Physical Activity, Comorbidity, Functional Capacity, Peripheral Muscle Strength and Depression in Breast Cancer Survivors. Asian Pac J Cancer Prev 2015;16:585-589. [CrossRef]

13. Çıtaker S, Kafa N, Kanık HZ, Uğurlu M, Kafa B, Tuna Z. Translation, cross-cultural adaptation and validation of the Turkish version of the Lower Extremity Functional Scale on patients with knee injuries. Arch Orthop Trauma Surg 2016;136:389-395. [CrossRef]

14. Bennell KL, Wrigley TV, Hunt MA, Lim BW, Hinman RS. Update on the role of muscle in the genesis and management of knee osteoarthritis. Rheum Dis Clin North Am 2013;39:145-176. [CrossRef]

15. Liikavainio T, Lyytinen T, Tyrvainen E, Sipila S, Arokoski JP. Physical function and properties of quadriceps femoris muscle in men with knee osteoarthritis. Arch Phys Med Rehabil 2008;89:2185-2194. [CrossRef]

16. Palmieri-Smith RM, Thomas AC, Karvonen-Gutierrez C, Sowers MF. Isometric quadriceps strength in women with mild, moderate, and severe knee osteoarthritis. Am J Phys Med Rehabil 2010;89:541-548. [CrossRef]

17. Lewek DM, Rudolph SK, Snyder-Mackler L. Quadriceps femoris muscle weakness and activation failure in patients with symptomatic knee osteoarthritis. J Orthop Res 2004;22:110-115. [CrossRef]

18. Hortobagyi T, Westerkamp L, Beam $\mathrm{S}$, et al. Altered hamstringquadriceps muscle balance in patients with knee osteoarthritis. Clin Biomech 2005;20:97-104, [CrossRef]

19. Culvenor AG, Ruhdorfer A, Juhl C, Eckstein F, Øiestad BE. Knee Extensor Strength and Risk of Structural, Symptomatic, and Functional Decline in Knee Osteoarthritis: A Systematic Review and Meta-Analysis. Arthritis Care Res 2017;69:649-658. [CrossRef]

20. Harrison AL. The influence of pathology, pain, balance and selfefficacy on function in women with osteoarthritis of the knee. Phys Ther 2004;84:822-831. [CrossRef]

21. Gürkan HS, Kırdı N, Tüzün EH, Atilla B. Balance problems in patients with knee osteoarthritis, evaluation of physical functionality and quality of life. Academic Geriatrics Congress, 2010;20-24. verbal notice.

22. Chun SW, Kim KE, Jang SN, et al. Muscle strength is the main associated factor of physical performance in older adults with knee osteoarthritis regardless of radiographic severity. Arch Gerontol Geriatr 2013;56:377-382. [CrossRef] 